remodelling rate were $100 \%(4 / 4)$ in stone disease, $100 \%(1 /$ 1 ) in post-cholecystectomy related stricture and $58.3 \%(7 / 12)$ in chronic pancreatitis.

\begin{tabular}{llll} 
Abstract PTH-037 Table 1 & Patient baseline characteristics \\
\hline & $\begin{array}{l}\text { Malignant } \\
(\mathbf{n}=142)\end{array}$ & $\begin{array}{l}\text { Benign } \\
(\mathbf{n}=19)\end{array}$ & $\begin{array}{l}\text { Indeterminate } \\
(\mathbf{n}=5)\end{array}$ \\
\hline Mean age (range) & $77(44-101)$ & $55(28-95)$ & $84(78-89)$ \\
Male gender, $\mathrm{n}(\%)$ & $84(59.1 \%)$ & 15 & $1(20 \%)$ \\
& & $(78.9 \%)$ & \\
No. of ERCPs prior & 90 & 2 & 3 \\
8. 0 & 42 & 8 & 1 \\
9.1 & 7 & 3 & 1 \\
10.2 & 1 & 3 & 0 \\
11.3 & 0 & 0 & 0 \\
12.4 & 2 & 3 & 0 \\
$13 . \geq 5$ & & & \\
Mean no of days between last and & $113(4-963)$ & $164(9-$ & $58(34-82)$ \\
current ERCP, $n$ (range) & & $1325)$ \\
\hline
\end{tabular}

$\mathrm{n}=$ number of patients

\begin{tabular}{llll} 
Abstract PTH-037 Table 2 & \multicolumn{4}{l}{ Adverse events } \\
\hline & $\begin{array}{l}\text { Malignant } \\
(\mathbf{n}=153)\end{array}$ & $\begin{array}{l}\text { Benign } \\
(\mathbf{n}=27)\end{array}$ & $\begin{array}{l}\text { Indeterminate } \\
(\mathbf{n}=5)\end{array}$ \\
\hline Early & 6 & 0 & 0 \\
14. Biliary infection & 2 & 0 & 0 \\
15. Pancreatitis & 2 & 0 & 0 \\
16. Bleeding & 1 & 0 & 0 \\
17. Perforation & 2 & 0 & 0 \\
18. Repeat ERCP within 7 days & 2 & 1 & 0 \\
19. Others & & & \\
Late & 25 & 0 & 0 \\
20. Stent occlusion & 10 & 8 & 1 \\
21. Stent migration & 1 & 0 & 0 \\
22. Biliary infection but patent stent & & & \\
on ERCP & & &
\end{tabular}

$\mathrm{n}=$ number of ERCPs

Abstract PTH-037 Table 3 Stent dysfunction in malignant strictures

\begin{tabular}{llll}
\hline $\begin{array}{l}\text { Malignant } \\
(n=153)\end{array}$ & $\begin{array}{l}\text { FCSEMs } \\
(n=30)\end{array}$ & $\begin{array}{l}\text { FCSEMs } \\
+ \text { plastic* } \\
(n=1)\end{array}$ & $\begin{array}{l}\text { UCSEMs } \\
(n=122)\end{array}$ \\
\hline $\begin{array}{l}\text { Stent occlusion } \\
\text { Stent migration }\end{array}$ & 5 & 0 & 20 \\
\hline
\end{tabular}

$\mathrm{n}=$ number of ERCPs

* plastic stent inserted for anchoring purposes to prevent stent migration

\begin{tabular}{llll} 
Abstract PTH-037 & Table 4 & Stent dysfunction in benign strictures \\
\hline Benign $(\mathrm{n}=27)$ & $\begin{array}{l}\text { FCSEMs } \\
(\mathrm{n}=22)\end{array}$ & $\begin{array}{l}\text { FCSEMs+plastic* } \\
(\mathrm{n}=5)\end{array}$ & $\begin{array}{l}\text { UCSEMs } \\
(\mathrm{n}=\mathbf{0})\end{array}$ \\
\hline Stent occlusion & 0 & 0 & 0 \\
Stent migration & 7 & 1 & 0 \\
\hline
\end{tabular}

$\mathrm{n}=$ number of ERCPs

* plastic stent inserted for anchoring purposes to prevent stent migration
Conclusions Our data appears comparable to larger studies. In our cohort there is a clear contrast in stent dysfunction between FCSEMs and UCSEMs. Biliary sepsis post SEMs insertion seems higher than the published European data and this probably reflects the change in practice in our hospital for advocating against antibiotic prophylaxis. Plastic stent within FCSEMs did not significantly reduce the risk of stent migration.

\section{PTH-038 MANAGEMENT OF BILIARY COMPLICATIONS FOLLOWING LIVER TRANSPLANTATION: 10 YEARS EXPERIENCE}

Vinod Hegade*, Theodoros Tsirlis, Sandra Latimer, Derek Manas Richard, Manu Nayar, Kofi Oppong, Mark Hudson, John Leeds. Freeman Hospital, Newcastle Upon Tyne, UK

\subsection{6/gutjnl-2018-BSGAbstracts.59}

Introduction Biliary complications after liver transplantation (LT) are common and some risk factors have been identified. Optimum endoscopic management including use of fully covered self-expanding metal stents (fcSEMS) in patients following LT requires evaluation. We aimed to identify risk factors for biliary complications following LT and present our experience of endoscopic management.

Methods Retrospective analysis of adult LT's performed at our centre. Patient demographics, donor characteristics, transplantation data (including graft type; donation after brain death (DBD) or cardiac death (DCD)), biliary complications and subsequent management were recorded and the DRI calculated. The cohort consisted of all LT performed between 2007 and 2016. Univariate and multivariable analysis was used to identify risk factors for biliary complications and ascertain factors associated with biliary stricture resolution.

Results A total of $353(n=322$ DBD and $n=31$ DCD) patients were included of which $80(22.7 \%)$ patients developed biliary complications. DCD patients had a higher prevalence of biliary complications compared to DBD patients (16/31 vs 64/ 322, OR 4.3, 95\% CI 2.0-9.2, $\mathrm{p}=0.0002$ ). Biliary leak rate was not significantly different (DCD 9.7\% vs DBD $8.1 \%$ ) but biliary strictures were more common in DCD patients compared to DBD (12/31 vs 36/322, OR 5.0, 95\% CI 2.3-11.2, $\mathrm{p}=0.0001)$. Biliary strictures were also associated with higher DRI $(1.97$ vs $1.76, p=0.015)$. Hepatic artery thrombosis rate was the same in both groups $(9.3 \%$ vs $7.2 \%, p=0.74)$. Multivariable analysis showed that only DCD was independently associated with biliary strictures (adjusted OR 4.6, 1.9-11.2, $\mathrm{p}=0.0007) .21 / 80$ with biliary complications underwent surgical $(n=8)$, radiological $(n=8)$ or conservative $(n=5)$ management. The remainder underwent ERCP; 42 patients had 116 procedures for strictures, 19 patients had 35 procedures for biliary leak and 12 had 20 procedures for stone disease (some multiple indications). There were no differences in stricture resolution between DCD and DBD (6/10 vs 21/32, p=ns). Per stent analysis showed higher stricture resolution rates following fcSEMS insertion compared to plastic stents $(18 / 20$ (90\%) vs $17 / 69(24.6 \%)$ respectively, $\mathrm{p}<0.0001)$.

Conclusion Biliary complications are associated with DCD livers. Endoscopic management of biliary complications leads to high resolution rates but patients undergo a high volume of procedures for strictures. fcSEMS had a higher stricture resolution rate compared to plastic stents. 